Chong-Ming Lim

\title{
Public Reason, Compromise within Consensus, and Legitimacy
}

\begin{abstract}
A central idea of public reason liberalism is that the exercise of political power is legitimate when supported only by reasons which all citizens accept. Public reason serves as a necessary standard for evaluating the legitimacy of political decisions. In this paper, I examine the directive to employ public reason, from citizens' perspective. I suggest that employing public reason potentially involves them engaging in different types of compromise. I consider how acknowledging these compromises sheds light on public reason liberalism. Public reason may not offer a necessary standard for evaluating the legitimacy of decisions, and the evaluation it offers may not have great weight relative to other moral and political considerations.
\end{abstract}

\section{Introduction}

How should we organise our political institutions, and thus common life with others, given pervasive and deep disagreements about the nature of the truth, the good, and justice? As a common story goes: since John Rawls, there has been a renewed and deeper recognition of how citizens' cooperative relationships (through these institutions) with each other profoundly shape their life prospects, in terms of what they can expect to be and how well they can hope to do (Rawls 1999a, pp. 6-7). Citizens, however, disagree about how these relationships are specified and organised - partly due to their different comprehensive views. Comprehensive views cover most, if not all, aspects of human life. Some of these views are religious in nature; others are not. Crucially, they contain ideals "of what is of value in human life", including human beings' relationships with their families, associates, environment, and their place in the universe writ large (Rawls 2005, p. 13). They inform people's political values and conceptions, which come into conflict in a pluralistic world. Yet collective decisions have to be made. The challenge is to create a common life together in a way that respects these disagreements without the unacceptable use of state power by some over others.

Consider the following, broad-stroke presentation of public reason liberalism, which is sometimes regarded as one of the "standard" responses to these disagreements. It requires that political decisions (or cooperative relations more generally) are supported by reasons which are acceptable to all citizens from the perspectives of their plural comprehensive views (Rawls 1997, p. 766). Their disagreements are to be negotiated by restricting themselves to using only such public reasons. ${ }^{1}$ The considerations from their comprehensive views are to be bracketed - set aside, and not to be invoked.

\footnotetext{
${ }^{1}$ This is one of two dominant interpretations of Rawls' political liberalism, known as the consensus model of public reason. Its main competitor is the convergence model, according to which public reason requires only that the decisions or relations themselves are acceptable to all citizens, without any accompanying restrictions on what reasons citizens regard as supporting them. For further discussions, see (D'Agostino 1996; Vallier 2011, pp. 262-264; Lister 2011). In this paper, I focus on the consensus account of public reason. I leave open the questions of whether and how my discussions apply to the convergence account, and also about their implications for the choice between the two accounts.
} 
Rawls describes the source of public reasons as the "shared fundamental ideas implicit in the public political culture" (Rawls 2005, p. 100). This culture comprises their existing political institutions, how they have been understood, and even historical texts and documents that are common knowledge (Rawls 2005, pp. 13-14). The content of public reason is filled in by a family of liberal political conceptions of justice. These conceptions are liberal in that they affirm certain key features of liberalism. They specify certain basic rights, liberties and opportunities, accord them a special priority relative to other values, and include measures ensuring that citizens have adequate means to intelligently and effective make use of them (Rawls 1999a, pp. 581-582; 2005, p. 223). They are political in that they apply only to a society's basic social and political institutions, are independent of any particular comprehensive view, and must draw from ideas implicit in the public political culture (1999a, p. 584). These political conceptions - along with the public reasons they contain - are (to be) embedded in each citizen's comprehensive views (2005, p. 387). This occurs when citizens find deeper non-public considerations within their own views to support and justify a political conception of justice and its reasons. Such affirmation is moral. It is not supported by pragmatic reasons of self- or group-interests, and does not hinge on the mere balance of forces or political power (Rawls 1999a, p. 573; 1999b, pp. 426-432). When all citizens manage to fit any one member of a family of liberal political conceptions of justice into their comprehensive views, an overlapping consensus is constituted (2005, p. 388).

According to public reason liberalism, political decisions are legitimate when supported only by public reasons. When decisions are supported by non-public considerations - which are not regarded as reasons from plural comprehensive views - they violate the requirement of public reason, and are illegitimate. Understood this way, public reason may be taken as a necessary standard for evaluating the legitimacy of political decisions (Enoch 2015, p. 115). ${ }^{2}$

Public reason liberalism is set against the background of the disagreements between reasonable citizens in a well-ordered society. Reasonable citizens are described as "not moved by the general good as such but desire for its own sake a social world in which they, as free and equal, can cooperate with others on terms all can accept" (Rawls 2005, p. 50). Further, they accept the "burdens of judgement" which are the "hazards involved in the correct (and conscientious) exercise of our powers of reason and judgment in the ordinary course of political life" (2005, pp. 55-56). When citizens accept the burdens of judgement, they accept that people may - because of the free exercise of reason - reasonably come to different and conflicting answers about what is true and good. They do not regard such reasonable pluralism as an "unfortunate condition of human life" (2005, p. 37). This lends motivation for pursuing public reason as a way of organising their common lives together since doing so is a way of ensuring that the decisions reached are acceptable to all. Of course, these citizens have comprehensive views which may conflict with the values underlying, and within, public reason. However, for these citizens, the political values which justify the employment of public reason are "very great values and not easily overridden" (Rawls 2005, p. 139), relative to the considerations within their comprehensive views. Because of this, they may put aside the considerations from their comprehensive views, for those of public reason.

\footnotetext{
${ }^{2}$ Here, I understand public reason as an expression of the principle of legitimacy, concerning the exercise of political power (Rawls 1997, p. 767; 2005, p. 217; Peter 2007). I set aside Rawls' second understanding of public reason, as an ideal regulating how public officials and citizens should speak deliberate in public fora (Rawls 1997, pp. 767, 798; 2005, p. 215).
} 
This stands in stark contrast with what we know about actual citizens. Actual citizens have a whole range of comprehensive views - not just those narrowly described as reasonable. A formulation of public reason which allows it to serve its function, would be one which allows its conclusions to be relevant, and contribute, to adjudicating these actual citizens' disagreements. Suppose it were otherwise - that public reason applies only to disagreements between ideally-described "reasonable citizens". In such a case, the conclusions of public reason may well be regarded as irrelevant to how actual citizens regard and negotiate their disagreements. Additionally, when the considerations within their comprehensive views conflict with those of public reason, actual citizens neither necessarily nor automatically judge that the latter conclusively outweigh the former. ${ }^{3}$

Many justifications have been given for employing public reason. Perhaps testament to the reality of pluralism, various answers have been given. For example, Joshua Cohen argues that employing public reason is justified by the value of democratic inclusion (Cohen 2011); James Boettcher and Charles Larmore argue that it is justified by that of respect (Boettcher 2007; Larmore 1999); Jonathan Quong argues that it is justified by the value of justice (Quong 2014); Andrew Lister argues that it is justified by civic friendship (Lister 2013), Chad Van Schoelandt, by "moral community" (Van Schoelandt 2015), and so on. These public reason philosophers disagree with each other about which value actually justifies the employment of public reason. Less attention, however, has been given to how citizens regard employing public reason as a way of addressing their disagreements, from the perspective of their comprehensive views.

I undertake this examination in this paper - specifically, of the directive to employ public reason, from the perspectives of citizens' comprehensive views. I suggest that they have to engage in several potential compromises in employing public reason. I consider how acknowledging these compromises sheds light on the status of the standard of legitimacy offered by public reason liberalism. Specifically, public reason may not be a necessary standard for evaluating the legitimacy of political decisions, and moreover, its evaluation may not have great weight relative to other moral and political considerations.

\section{$1 \quad$ Public reason and compromise}

Recall that citizens have different comprehensive views about the truth and good, and disagree with each other because of these views. From their perspectives, the ideal situation

\footnotetext{
${ }^{3}$ The situation is not easily ameliorated by positing the above conception of reasonable citizens as an ideal for actual citizens. Here and again, the relevant question is: for whom? In posing the question, we see that the ideal will again be subject to disagreements stemming from individuals' plural views. Positing the conception as an ideal does not make it immediately shared or shareable by individuals with plural views. Additionally, recall that public reason is invoked to adjudicate the problem of disagreements stemming from citizens' comprehensive views. It presents a way through which people who disagree morally may nevertheless find ways of living together. It may be a surprising turn of events if what is needed to solve the problem turns on moral education - of emulating a specifically-described ideal citizen for whom employing public reason is the accepted conflict-resolution strategy. Moreover, if some form of moral education is the answer, why may we not simply begin with it in our attempt to adjudicate disagreements? Why should we go along with public reason philosophers, down a circuitous route, only to reach what seems to be a similar conclusion?
} 
would be one in which their comprehensive view determines (or significantly influences) the political decisions that are made. How would they judge the political values that have been given as justifications for employing public reason? ${ }^{4}$

A note before proceeding. My discussion of the employment of public reason is not held at a very general level. Instead, I am concerned with specific issues or political decisions. That is, I take it that citizens deliberate, on each issue, about whether to adjudicate their disagreements by employing public reason, by other means, or even by refusing to have a decision. Their commitment to employing public reason for a specific issue does (and need) not carry over to other issues. This level of specificity also allows us to be clearer about the stakes involved, at each point, in asking citizens to employ public reason.

First, citizens may not judge any (or all) of the political values as actually justifying the employment of public reason in a particular case. The acceptability of reasons as it features in the lives of individuals is intimately tied to their comprehensive views. Since there is a plurality of such views, there will be different judgements about whether any value actually justifies the employment of public reason. A value which has been offered as a justification for employing public reason may be accepted by one individual, but rejected by another. We may not have to go far to find evidence for this. As we have seen above, public reason philosophers disagree among themselves about which of the values actually justifies employing public reason.

Second, and supposing that all citizens judge that a particular value actually justifies public reason in a particular case, there is still the question of the weight of that value relative to the considerations from within their comprehensive views. Very likely, the latter are accorded greater weight. This is because they are regarded as expressing the "full light of reason and truth" (Raz 1990, p. 31), in contrast to the more contained scope of the political values. More generally, citizens with different views will judge the weight of any given value differently. Some may regard the candidate values as sufficiently weighty, and conclusively in favour of employing public reason, whereas others may judge the same values to be trivial.

\footnotetext{
${ }^{4}$ Here, I am side-stepping some complications. In modern democracies, and certainly in Rawls' well-ordered society, political decisions are made by politicians (in their role as legislators) or public officials more generally, rather than directly by citizens. As with others within the debates within public reason, I take it that such public officials accurately and unproblematically represent the views of their constituencies - that is, the views of citizens. This picture makes a number of simplifying assumptions. First, that any constituency to be represented is homogenous in terms of their comprehensive views, such that no further input is required on behalf of those who represent them, and which may subsequently be a source of disagreement. Second, that the public officials do not have comprehensive views in tension, or outright conflict, with those of their constituencies. Third, that public officials do not have any other aims beyond representation - importantly, not even common-good or other perfectionist aims, when their constituencies do not regard them as important. In sum, representation is not a simple relationship. Jane Mansbridge (2003) provides a detailed account of the different forms of representation of citizens (and their claims and interests) in modern democracies. These are constituted by different relationships between citizens' claims and interests, and those of the officials who represent them. This means, also, that there are complications with asking citizens to ideally model the deliberations of legislators (Rawls 2005, pp. 444-445).

While I think that public reason liberalism should acknowledge these complications, and explain how the weight of the available justifications for employing public reason may change in view of them, doing so is beyond the scope of this paper.
} 
Given this, we may say that any value offered as a justification for employing public reason is at best only pro tanto in nature. In effect, it is a consideration in favour of employing public reason, but is not necessarily conclusive. The claim that such values are pro tanto in nature, is arrived at by taking citizens' plural comprehensive views seriously. Different views will give rise to different evaluations of whether any value actually pro tanto justifies employing public reason, and their weight relative to other considerations (within the views). These considerations may also be regarded as either pro tanto justifying (or rejecting) the employment of public reason. Citizens employ public reason when they judge that the available pro tanto justifications for doing so are undefeated by the considerations from their comprehensive views.

Importantly, the force of pro tanto justifications persists even after their defeat by other considerations. They stand in contrast to prima facie justifications. When a prima facie justification is defeated, the supporting consideration either no longer applies, or loses its justificatory force, or both. However, when a pro tanto justification is defeated, its consideration still applies (despite being defeated) and retains its force. ${ }^{5}$ Framing the values and considerations this way shows that even when citizens judge that the political values conclusively justify employing public reason, the considerations within their comprehensive views still have force - and vice versa. That they remain in force, contributes to citizens' thoughts that the employment of public reason is less than ideal - they cannot or do not (entirely) fulfil the demands of their comprehensive views.

Because of this, we may say that citizens engage in a kind of compromise when they employ public reason. Here, their compromise consists in their refraining from appealing to the considerations in their comprehensive views, to determine how the political decision at hand is to be settled (Lister 2007, p. 16). I adopt a basic conception of compromise. ${ }^{6} \mathrm{~A}$ compromise occurs when individuals settle for choices that they regard as less-than-ideal. A compromise may be made with other people, or it may not. Because this is a minimal conception of compromise, it allows more room for a wider range of phenomena to be understood as compromise. In the rest of this section, I briefly enumerate several more compromises that citizens may engage in, when employing public reason.

Another potential compromise when citizens employ public reason lies in their recognition of each other as people with whom they can converse and cooperate, and to whom justification is to be given. They cease seeing each other as people over whom they must thoroughly triumph, or over whom their comprehensive views may be implemented without acceptance. For them to even enter (constructive) conversation requires them to set aside their beliefs that their opponents are fundamentally misguided and thus need not (or do not deserve to) be conversed with. This kind of compromise should not be downplayed. In many conflicts, the disputants are unwilling to make this crucial move (Margalit 2010, p. 42). Yet these views do not disappear. From each's perspective, entering into conversation involves a compromise they do something which is less-than-ideal, and moreover deviates from their firmly-held beliefs. This explains why these decisions are often accompanied by accusations of "sellingout" on one's beliefs, made by those who refuse to bracket their beliefs and who are not

\footnotetext{
${ }^{5}$ Andrew Reisner (2013) provides a detailed discussion of the distinction, as applied to 'oughts'.

${ }^{6}$ See (Fumurescu 2013) for a political and philosophical survey of the idea of compromise, and the discussions surrounding it.
} 
motivated to begin conversation. A clarification: the disputants need not supplement their recognition of each other as being owed justification, with the further thought that they are moral equals - though doing so is probably helpful for establishing fruitful conversation and stable cooperation. Their recognition of each other as being owed justification, even if purely in pragmatic terms, is sufficient for us to characterise it as involving a compromise.

Yet another compromise may consist in citizen's refraining from appealing to their comprehensive views in their discussions about the weight of the various public reasons. One aspect of comprehensive views is that they cover "all recognized values and virtues within one rather precisely articulated system" (Rawls 2005, p. 13). Within different systems, the available public reasons are accorded different weight. Citizens compromise when they refrain from relying on their views' ranking or prioritisation of reasons in their discussions. Even if one judges that a certain reason should outweigh another, the supporting considerations they invoke cannot be taken simply from their comprehensive views without consideration of their acceptability to others. Consider one interpretation of the Imago Dei doctrine, according to which human freedom trumps all other considerations in virtue of it being that which reflects human beings' special relationship with God. A believer may hence regard all limits on human freedom with great suspicion, if not reject them outright. Yet she cannot publicly invoke the Imago Dei doctrine to support her prioritisation of human freedom, if it is not also acceptable to others.

Citizens may also compromise on how a particular issue is framed. Some disagreements, for example, seem to reduce to discrete, yes or no, questions. For example, in the disputes about abortion, "the most crucial point of contention is a discrete question: either a woman has the right to abort a pregnancy in her first trimester simply because she does not wish to carry it to term, or she does not" (May 2005, p. 347). Here, the compromise may consist in how the issue is framed. For example, rather than have the decision be about women's absolute right to abortion, it can be framed as one concerning the circumstances in which women have the right to abortion, or what circumstances in which women are legally permitted to abort. ${ }^{7}$ Changing the framing of the disagreement will involve a compromise because both parties are likely to regard it as far from ideal or even fundamentally misguided. At its roots, altering the framing of a disagreement is a form of attending to its content. Both parties are likely to think that the new framing does not accurately reflect what the issue is truly about. For those who believe that women have the right to abort a pregnancy, this is regarded as erroneously introducing qualifications to something which they regard as being absolute. For their opponents, this may involve a sell-out on their belief that human life in any form is sacred. But whereas the issue of possessing an absolute right admits of little or no compromise, altering how the disagreement is framed - no matter how reluctantly - opens up space to locate a middle ground and overcomes decisional paralysis. ${ }^{8}$

Throughout these potential compromises, the parties involved do not forsake the view that their comprehensive views are correct, and offer the ideal response to the issue in concern. Their compromises do not commit them to the falsity or triviality of their views. Nor do they

\footnotetext{
${ }^{7}$ Avishai Margalit suggests that there is a radical element to reframing contentious issues: when he argues that Jews and Muslims may reframe their disagreements concerning the sovereignty of Temple Mount in Jerusalem to one concerning its use (2010, p. 50).

${ }^{8} \mathrm{I}$ am not endorsing a compromise of this sort. My point is only that even seemingly intractable disagreements may admit of some compromise of this sort.
} 
adopt a new position on how things should ideally be done. If they did, there would not be a compromise - they would have just changed their minds (Weinstock 2013, p. 540). Rather, they set aside the considerations within their comprehensive views, seeking terms of cooperation acceptable to all. From each's perspective, concessions are made which constitute their cooperation.

This sampling of different potential compromises, while brief, shows how compromises may well be involved in the employment of public reason, from citizens' perspectives, informed by their comprehensive views. ${ }^{9}$ This aspect of citizens' relationships with each other appears to be largely unaccounted for by public reason liberalism (or Rawlsian accounts of political liberalism more generally). This has prompted political theorists to seriously contemplate moving beyond them (Wendt 2013, 2016).

\section{Compromise and legitimacy}

Recall that public reason is intended to be a necessary standard for evaluating the legitimacy of political decisions. Decisions are legitimate when they are supported only by public reasons. Citizens are asked to aim at decisions that are legitimate in this sense, and avoid those which are not. As we have seen, employing public reason may involve citizens' engaging in several compromises. These potential compromises occur at two broad stages when entering into cooperation (as when they refrain from employing considerations from their comprehensive views, and use only public reasons), and during the course of specifying the terms of cooperation (as when they refrain from using their comprehensive views' prioritisation of reasons, and when they frame the issue in a way different from what their views require). The acknowledgement of the potential compromises that citizens have to engage in, when employing public reason, has implications for how we understand public reason liberalism's idea of political legitimacy. Specifically, we see that public reason may not offer a necessary standard for evaluating the legitimacy of decisions, and moreover that its evaluation may not have great weight relative to other moral and political considerations.

\footnotetext{
${ }^{9}$ An unexpected payoff of rendering citizens' employment of public reasons as involving compromise, is in identifying a new kind of compromise in addition to the "integrative" and "substitutive" compromises commonly cited in the discussions concerning the general categorisation of different kinds of compromise. Integrative compromises are those in which the eventual decision contains elements of the initially conflicting positions. This may be done via drawing from and balancing elements of their different views which both sides deem most crucial to their interests. Substitutive compromises replace the conflicting positions with a different position regarded as less-than-ideal for both parties, but nevertheless acceptable (Weinstock 2013, pp. 539-540). The compromise involved in settling on public reasons does not involve the parties directly settling on, or being committed to, intermediate positions. Instead, the analyses here about public reason reveal the possibility of compromising by settling on the reasons which enter as appropriate for formulating their future collective decisions and cooperation. This kind of compromise allows for the possibility that the eventual decision may be either integrative or substitutive, or both, depending on the issue. In our context, this foregrounds the relative priority or fundamental nature of the common reasons which the parties are committed to for future decisions. This allows us, when intermediate decisions are rejected, to have a clearer picture of the source of disagreement - as lying in reasons deemed unacceptable to serve as the bases of cooperation. There may yet be additional kinds of compromise, as we look closer at real cases. This claim learns from the insight that "different types of conflict will generate different sorts of compromise" (Bellamy/Hollis 1999, p. 65).
} 
Consider, first, citizens' entering into cooperation. As discussed earlier, citizens employ public reason to adjudicate their disagreements when they judge that the available justifications for doing so defeat the considerations within their comprehensive views. Such judgements, however, should be understood as being made against the background of their willingness to cooperate to reach a common political decision in a particular case. That is, in other cases, they may think that no political decision is needed, desirable, or even possible. For instance, they may regard it as unnecessary for decisions regulating the internal dynamics of private organisations such as businesses or religious institutions, that it is undesirable to have decisions regulating family dynamics such as how spouses and their children relate to each other, or that it is impossible to have decisions about how disputed territories are shared. The issue is left open concerning the extent and shape of their cooperation. We need not posit that the issues for which they are willing to cooperate takes the exact form of the basic institutions of society. Their cooperation may concern only a few issues, and thus constitute a minimally shared life. Or it may be thick, comprising many cooperative decisions constituting a richly shared life. In these situations, it is unnecessary to employ public reason. Citizens do not regard there as being any common political decision which needs to be made - and much less one that has to be supported by reasons acceptable to all. In effect, they leave that issue open and unregulated by a common decision. ${ }^{10}$

I leave open what considerations undergird their willingness to cooperate in any particular case. What is important is simply that they are willing to do so. In this case, the pressure to provide a further explanation for their willingness may not yield fruitful answers. If we are to respect the different, and often mixed, reasons that people have for cooperation, this general claim may be as specific as we can get. Moreover, providing such an explanation runs the risk of speaking about their motivations presumptively - which may not sit well with our wanting to take the pluralism in their views seriously.

Our discussions of the compromises that citizens have to engage in, when employing public reason, highlights the stakes that are involved in their doing so. From their perspectives, employing public reason is not always easy. Frequently, it may be very difficult for them to side-line and refrain from using the considerations from their comprehensive views, just to reach a common political decision using public reason. The proffered justifications for employing public reason may sometimes not be weighty enough for them, to (decide to) employ public reason. They may judge it more important to appeal to and employ the considerations from their comprehensive views. This, however, does not mean that they give up on pursuing cooperation through a common political decision. That the justifications for employing public reason are insufficiently weighty, simply means that citizens will not adjudicate their disagreements through public reason. They may yet reach decisions by other means.

One way they may do so, is by appealing to the considerations within their comprehensive views, but also compromise by incorporating and accommodating such considerations within

\footnotetext{
${ }^{10}$ When decisions are not made in modern societies, there is often a status quo - of a pre-existing decision - to fall back upon. This, however, is not always true. My formulation, being more general, accommodates citizens' potential unwillingness to reach common political decisions for novel cases not covered by pre-existing decisions.
} 
the political decision itself. For instance, in discussing the United States of America's Tax Reform Act of 1986, Amy Gutmann and Dennis Thompson observe that

\begin{abstract}
All supporters of the [Tax Reform Act] gained something they desired, but all also made concessions that flew in the face of their most principled reasons for supporting comprehensive tax reform in the first place. Democrats wanted to end loopholes for special interests and the wealthy, but they also agreed to radically lower the top tax rate (from 50 percent to 28 percent). Republicans wanted to lower marginal tax rates, but they also agreed to eliminate $\$ 30$ billion annually in tax deductions, which resulted in the wealthy contributing a higher percentage of income-tax revenues than they previously had done (Gutmann/Thompson 2010, p. 1126).
\end{abstract}

In this case, the disputants compromise by allowing the final decision to contain clauses that they do not regard as being supported by reasons from their perspectives. This means that there are (different) portions of the decision that are not supported by shared reasons. Here, we may say that they are compromising on the content of the decision directly. They do not employ public reason, but nevertheless reach a decision. We may see them as motivated by a willingness to reach a decision, because they think that "tax reform was long overdue" (Gutmann/Thompson 2010, p. 1126), and that they would rather have marginal improvements on some fronts (while conceding on others), than no decision at all. More generally, and for other cases, disputants may judge that a lack of, or prolonged delay in reaching, decisions is costly - as it may unduly prolong an undesirable status quo, or lead to unpalatable long-term consequences. ${ }^{11}$

Are such decisions illegitimate? According to public reason, they are. This is because they are not supported only by considerations which all parties involved regard as reasons. This means that there are points at which some may regard themselves as being unacceptably without reason - subject to state power.

However, these decisions may still be legitimate in a different, more minimal sense. That is, they are legitimate insofar as citizens accept a decision for whatever reason - even if (part of) the decision is supported by considerations they do not regard as reasons. The parties' acceptance of the decision is, in such cases, stripped of the strong endorsement which public reason liberalism requires. Specifically, the parties need not integrate the considerations supporting the decision into their comprehensive views. This way, decisions may be regarded as legitimate despite their sustained disagreements with (portions of) them.

This more minimal sense of legitimacy helps us to better understand some kinds of fundamental disagreements fuelled by comprehensive views. Consider the example of the Quakers. Rawls describes them as endorsing the principles (including the accompanying organisation and incorporation of public reasons) of the political conceptions of justice which shape the society's institutions and laws through political decisions. However, they nevertheless have fundamental disagreements - informed by their comprehensive views -

\footnotetext{
${ }^{11}$ As is the case of the delay in introducing legislation, in many countries, aimed at curbing carbon emissions to slow down, and mitigate the effects of, climate change, among others.
} 
with existing institutions, policies, or enacted legislation. In expressing their disagreement, they engage in what Rawls describes as "witnessing" (Rawls 1999a, pp. 594-595, footnote 57). Rawls does not say very much about what is exactly involved, except to note that it does not involve civil disobedience or conscientious refusal. Presumably, it involves engaging other citizens through established channels of communication and debate, or voting against existing institutions and legislation.

The question arises as to why the Quakers would endorse, in the first place, a political conception and all its constituent reasons, some of which are opposed to what they stand for. On Rawls' account, such endorsement has to be fit into their comprehensive views. Yet in this case, they regard there to be some unacceptable reasons, which cannot be fit into their views. For them, the mere fact that they are born into a society where these reasons and conceptions are operative for others, may not count towards, and may be no guarantee of, the kind of endorsement Rawls requires. How do we square their purported endorsement, and their commitment to their comprehensive views, without positing a deep inconsistency in their beliefs, or split in their personalities ${ }^{12}$

Understanding decisions as legitimate in this sense, helps us to better understand this situation. Such citizens can regard these decisions as legitimate, merely because the decisions are acceptable in light of their willingness to cooperate with others. They do not need to endorse all the content of the decisions, or the considerations supporting them. Thus, they do not commit themselves to any deep inconsistency in accepting political decisions as legitimate, the contents of which they disagree. Moreover, they would not, in "witnessing" their disagreement, be open to accusations of inconsistency arising from their simultaneous affirmation of the very considerations which lead to decisions with which they disagree. They are also freed from the charge of hypocrisy, in their recognition that the existing institutions may be required, in a deep way, to support their survival and flourishing. ${ }^{13}$ Importantly, they are not committed to any future decisions on the basis of allegiance (which they may lack) to any particular considerations which support those (portions of) decisions with which they disagree. This leaves room for them to advance different conceptions for future issues.

If this more minimal sense of legitimacy is genuine, then public reason may not be a necessary standard for evaluating the legitimacy of political decisions. That is, citizens may judge decisions to be legitimate even if they violate the standard set by public reason liberalism. This is not all - a further worry arises when we think about the potential compromises that citizens make over the course of specifying the terms of their cooperation.

\footnotetext{
${ }^{12}$ Here, it is inadequate to point to the fact that for most people, their views may not be regarded as fully comprehensive. There is sufficient slippage, such that a given political conception may "cohere loosely" with the commitments of their incompletely-comprehensive views. Consequently, "many if not most citizens come to affirm their common political conception without seeing any particular connection, one way or the other, between it and their other views" (Rawls 1999b, p. 441). While this may be accurate, what it does is to solve the problem here by appealing to citizens' hastiness or ignorance. Moreover, we may rightly be less optimistic than Rawls, when he writes that citizens "might very well adjust or revise these [comprehensive] doctrines rather than reject the political conception" (Rawls 1999b, p. 441) after coming to notice the deep tensions upon careful reflections about their commitments. And most importantly, it leaves unanswered the issue of parties who disagree in light of their fully comprehensive views and thoroughly thought-out commitments.

${ }^{13}$ Many thanks to Stephen Snyder for urging me to clarify this.
} 
Recall that citizens also compromise by refraining from using their comprehensive views' ranking or prioritisation of values or reasons in their deliberations. That is, a political decision may be settled, which relies on according great weight to a particular value that does not have very much weight in some citizens' comprehensive views. For instance, a particular decision - say, concerning a country's membership in a particular union - may be primarily supported by the consideration of political community or sovereignty, understood in a specific sense. Many citizens may agree that political community or sovereignty understood in that sense are valuable, but reject that it has sufficient weight to determine the decision in the way that they did. That is, they may judge both that the considerations employed have little weight in relation to other public reasons, as well as to considerations within their comprehensive views. They may think that the considerations of economic prosperity, of protecting the vulnerable, of even regional community, each (or all) outweigh the considerations currently supporting the decision. In such a case, what is achieved by telling these dissenting citizens that the decision is legitimate because it is supported by considerations that they (all) regard as reasons? It does little to rehabilitate their view that the decision is wrong - because it relies too heavily on trivial values, and too little on important ones. ${ }^{14}$

That is to say, the evaluation that a particular decision is legitimate, may, in some cases, count for very little. If the reasons supporting a particular decision are regarded as trivial, the evaluation may not count for much. To illustrate further, suppose that all parties involved in a decision regard the consideration of 'being presented using beautiful prose' as indeed a reason for any political decision. Suppose further that this consideration is primarily (or even solely) relied upon, to deliver a particular political decision. This decision, on public reason terms, would be legitimate. Now, unless we can show that the consideration is accorded great weight by all citizens from the perspectives of their comprehensive views, it will be of little consolation to them that this decision is in fact legitimate in this way. Their judgements that the decision is wrong, and their rejection of it, are unlikely to be rehabilitated by the evaluation of that decision as legitimate. This worry is even starker when we consider compromises concerning how decisions are framed - which are often regarded as even more profound than those about the weight of the available reasons.

Put together, we see that public reason may not be a necessary standard for evaluating the legitimacy of political decisions. Decisions may be legitimate even though they fail to meet the requirement of public reason to be supported only by reasons acceptable to all. Additionally, the evaluation of political decisions as legitimate on public reason terms, may, in some cases, count for very little from the perspectives of some citizens - who disagree with how the decisions rely on the available reasons, or how the decision is framed. Public reason offers us but one way, among many others, of evaluating political decisions (Enoch 2015, pp. 138-139).

\footnotetext{
${ }^{14}$ Rawls appears to acknowledge this, when he writes that while citizens may disagree about which particular conception of justice (or its accompanying public reasons) is most reasonable, "they will agree that all are reasonable, even if barely so" (Rawls 1999a, p. 578). My point here is that their judgements that a particular political conception of justice (or its accompanying public reasons) are barely reasonable or acceptable, may count for very little. And echoing an earlier point, we must not assume that the citizens involved will automatically or easily accord the available public reasons great weight within their views.
} 
In this paper, I have considered the directive to employ public reason from the perspectives of citizens with plural comprehensive views. I observed that in employing public reason, they may engage in several types of compromises. The compromises occur at two broad stages when entering into cooperation (as when they refrain from employing considerations from their comprehensive view, and use only public reasons), and compromises during the course of specifying the terms of cooperation (as when they refrain from using their comprehensive views' prioritisation of reasons, and when they frame the issue in a way different from what their views require). I then considered how acknowledging these compromises sheds light on public reason liberalism. Public reason may not offer a necessary standard for evaluating the legitimacy of decisions, and its evaluation of the legitimacy of decisions may not have great weight relative to other moral and political considerations.

What can public reason philosophers do, in response to this gloomy discussion? It is open for them to argue that the legitimacy offered by public reason liberalism is the appropriate standard to aim for, in any given specific case. That is, they may argue that the fact (or possibility) that the decision in concern is legitimate in the way public reason requires, is more important than the plural values and considerations that citizens may bring to the table - including those that move them to cooperate on different terms, or forsake cooperation altogether. If so, citizens should neither settle for a more minimal sense of legitimacy, nor regard as trivial the evaluation that the decision is illegitimate on public reason terms. However, and depending on the issue for which a decision is required, such a position may not be easily taken. In disputes such as same-sex marriage, sex education, climate change, or animal rights, among others, it is not clear that it is more important to have decisions which are supported by reasons which all citizens can accept, than any of the other available nonpublic considerations. In such cases, we might think that imposing state power in a way that may be regarded as unacceptable by some, may be an evil we are willing to incur in order to do what is right. Public reason liberalism has to say more if it is to convince us otherwise.

\section{Bibliography}

Bellamy, Richard/Hollis, Martin (1999): “Consensus, Neutrality and Compromise". In: Bellamy, Richard/Hollis, Martin (Eds.): Pluralism and Liberal Neutrality. Portland: Frank Cass.

Boettcher, James W. (2007): "Respect, Recognition, and Public Reason”. In: Social Theory and Practice 33. No. 2, pp. 223-249.

Cohen, Joshua (2011): “Establishment, Exclusion, and Democracy's Public Reason". In: Wallace R. Jay/Kumar, Rahul/Freeman, Samuel (Eds.): Reasons and Recognition: Essays on the Philosophy of T.M. Scanlon. Oxford: Oxford University Press, pp. 256275.

D’Agostino, Fred (1996): Free Public Reason: Making It Up As We Go. New York: Oxford University Press. 
Enoch, David (2015): “Against Public Reason". In Sobel, David/Vallentyne, Peter/Wall, Steven (Eds.): Oxford Studies in Political Philosophy. Vol. 1. Oxford: Oxford University Press, pp. 112-142.

Fumurescu, Alin (2013): Compromise: A Political and Philosophical History. New York: Cambridge University Press.

Gutmann, Amy/Thompson, Dennis (2010): “The Mindsets of Political Compromise". In: Perspectives on Politics 8. No. 4, pp. 1125-1143.

Larmore, Charles (1999): "The Moral Basis of Political Liberalism". In: The Journal of Philosophy 96. No. 12, pp. 599-625.

Lister, Andrew (2007): "Public Reason and Moral Compromise". In: Canadian Journal of Philosophy 37. No. 1, pp. 1-34.

Lister, Andrew (2011): "Public Justification of What? Coercion vs Decision as Competing Frames for the Basic Principle of Justificatory Liberalism". In: Public Affairs Quarterly 25. No. 4, pp. 349-367.

Lister, Andrew (2013): Public Reason and Political Community. London: Bloomsbury Academic.

Mansbridge, Jane (2003): "Rethinking Representation". In: American Political Science Review 97. No. 4, pp. 515-528.

Margalit, Avishai (2010): On Compromise and Rotten Compromises. New Jersey: Princeton University Press.

May, Simon (2005): "Principled Compromise and the Abortion Controversy". In: Philosophy \& Public Affairs 33. No. 4, pp. 317-348.

Peter, Fabienne (2007): "Rawls' Idea of Public Reason and Democratic Legitimacy". In: Politics and Ethics Review 3. No. 1, pp. 129-143.

Quong, Jonathan (2014). “On the Idea of Public Reason”. In: Mandle, Jon/Reidy, David (Eds.): A Companion to Rawls. First edition. Oxford: Blackwell, pp. 265-280.

Rawls, John (1997): A Theory of Justice. Revised edition. Cambridge: Belknap Press.

Rawls, John (1999a): “The Idea of Public Reason Revisited”. In: Rawls, John: Collected Papers. Samuel Freeman (Ed.). Cambridge: Harvard University Press, pp. 573-615.

Rawls, John (1999b): “The Idea of an Overlapping Consensus”. In: Rawls, John: Collected Papers. Samuel Freeman (Ed.). Cambridge: Harvard University Press, pp. 421-448.

Rawls, John (2005): Political Liberalism. Expanded edition. New York: Columbia University Press.

Raz, Joseph (1990): "Facing Diversity: The Case of Epistemic Abstinence”. In: Philosophy and Public Affairs 19. No. 1, pp. 3-46.

Reisner, Andrew E (2013): "Prima Facie and Pro Tanto Oughts". In: LaFollette, Hugh (Ed.): The International Encyclopedia of Ethics. Chichester: Blackwell, pp. 4082-4086.

Vallier, Kevin (2011): "Convergence and Consensus in Public Reason". In: Public Affairs Quarterly 25. No. 4, pp. 261-279. 
Van Schoelandt, Chad (2015): "Justification, Coercion, and the Place of Public Reason". In: Philosophical Studies 172, pp. 1031-1050.

Weinstock, Daniel (2013): “On the Possibility of Principled Moral Compromise”. In: Critical Review of International Social and Political Philosophy 16. No. 4, pp. 537-556.

Wendt, Fabian (2013): "Introduction: Compromising on Justice". In: Critical Review of International Social and Political Philosophy 16. No. 4, pp. 475-480.

Wendt, Fabian (2016): Compromise, Peace, and Public Justification. London: Palgrave Macmillan. 